\title{
Competências para Inovar na Indústria Petroquímica Brasileira*
}

\author{
Flávia Chaves Alves \\ Escola de Química - UFRJ \\ José Vitor Bomtempo \\ Departamento de Engenharia Química - UFRJ \\ Paulo Luiz de Andrade Coutinho
}

Coordenador de P\&D - Petroflex Ind. e Com. Ltda.

Recebido: 21/2/2005 Aprovado: 17/8/2005

\section{RESUMO}

Este trabalho analisa a capacidade inovadora da indústria petroquímica brasileira com base na noção de competências para inovar. Partindo da visão da firma baseada em recursos (VBR), as competências para inovar são examinadas por meio de um questionário que procura identificar e avaliar o nível de desenvolvimento das competências da indústria em questão. Os resultados são analisados considerando-se as competências em quatro grupos: técnicas, organizacionais, relacionais e de meios. Os resultados indicam que a indústria detém níveis aceitáveis de competências em termos técnicos, mas nos demais grupos as competências existentes não parecem ser suficientes para que as empresas, e conseqüentemente o setor industrial que elas representam, possam ser consideradas inovadoras. As deficiências parecem ser particularmente acentuadas no grupo das competências organizacionais.

\footnotetext{
* Agradecemos os comentários e sugestões de dois pareceristas anônimos. Entretanto, são de nossa inteira responsabilidade as imperfeições que permaneçam no artigo.
} 
Palavras-Chave | Competências para Inovar; Indústria Petroquímica Brasileira; Inovação; Visão Baseada em Recursos

Códigos JEL | L65; O32

\section{ABSTRACT}

This paper analyses the innovation capability of the Brazilian Petrochemical Industry based on the notion of innovating competences. Using the Resource Based View (RBV) of the firm, the innovating competences are examined by applying a questionnaire to identify and evaluate the level of development of the present competences of the industry. The results are analyzed considering four groups of competences: technical, organizational, relational, and of means. It is shown that the industry accumulates sufficient technical competences. However, the other groups of competences are insufficient for the firms, and consequently the industry, to be considered innovative. The deficiencies are greater in the group of organizational competences.

KeYwords | Innovating Competences; Brazilian Petrochemical Industry; Innovation; Resource-based View

JEL CODES | L65, O32 


\section{Introdução}

A evolução permanente dos produtos e processos vem sendo reconhecida nos anos recentes como fundamental à saúde competitiva das empresas em quase todas as indústrias. As estratégias de inovação se tornam cruciais para a sobrevivência da maioria das empresas. Entretanto, essa capacidade inovadora parece depender de um conjunto complexo de fatores. $\mathrm{O}$ esforço inovador implica naturalmente uma capacitação tecnológica, mas não se restringe a ela. Mostramse necessárias também competências organizacionais (no âmbito interno das firmas) e relacionais (no âmbito das relações entre firmas).

Essa ótica de análise parece suscitar reflexões de grande interesse quando se observam as cadeias industriais das quais faz parte a indústria química no Brasil, em particular no caso dos segmentos mais tradicionais ligados à petroquímica, implantados no País há mais de duas décadas. Quais são as competências necessárias para inovar? Quais são as competências detidas pelas empresas? É possível levantar a hipótese de que a capacidade inovadora da indústria em questão é limitada por suas deficiências organizacionais e relacionais mais do que por sua suposta inferioridade tecnológica? É possível dizer que alguns obstáculos importantes residiriam antes na capacidade limitada de aplicação da tecnologia disponível do que na insuficiência de recursos para geração de novas tecnologias?

$\mathrm{Na}$ verdade, a indústria petroquímica brasileira é vista como pouco inovadora, tanto no que se refere ao nível do esforço empreendido em P\&D (Barros, 1998; Santana et al., 2003) quanto pelo posicionamento tecnológico da maioria das empresas (Coutinho, 2004). Segundo Coutinho (2004), predomina na petroquímica brasileira uma postura tecnológica mais reativa que pró-ativa, praticamente inexistindo empresas com postura de pioneiras. Na dinâmica de capacitação tecnológica e inovadora, sugerida por Kim (1999) para os países em desenvolvimento, a petroquímica estaria, considerando-se os estudos acima citados, mais próxima da imitação duplicativa do que de uma posição inovadora.

O presente trabalho pretende caracterizar a posição inovadora da petroquímica brasileira tomando como referência a noção de competências para inovar. Esta noção pode ser associada aos desenvolvimentos da corrente denominada resourcebased-view (RBV) (Barney, 1991; Collis \& Montgomery, 1995; Teece et al., 1997; Barney, 2001; entre outros) e aos esforços de caracterização do processo de 
capacitação inovadora no nível das firmas como os dos trabalhos de Nonaka e Takeuchi (1995) e Leonard-Barton (1995). Este trabalho busca contribuir com o esforço de pesquisa que visa conferir um conteúdo operacional às noções de recursos e competências, conforme foi identificado por Pavitt (2002), como um desafio importante das correntes evolucionistas em relação à noção de "innovating routines".

No que se refere à questão da capacitação inovadora de empresas brasileiras, o trabalho é complementar aos estudos de Figueiredo $(2001,2003)$ que exploram em profundidade o processo de capacitação tecnológica e inovadora intrafirma. Fora adotada aqui uma análise no nível da indústria ou setor, embora as variáveis de análise sejam identificadas no nível interno das empresas.

Este trabalho está organizado em quatro seções, além desta introdução. A seção 2 apresenta uma discussão da literatura em torno da visão das firmas com base na noção de competências. Discute-se, ainda nessa seção, a estrutura da proposta de avaliação das competências para inovar. A seção 3 apresenta a metodologia da pesquisa. Os resultados são apresentados e discutidos na seção 4 e a conclusão encontra-se na seção 5 .

\section{Argumentos teóricos}

\subsection{A visão das firmas com base na noção de competências}

O campo de estudo aberto pela abordagem da firma baseada em recursos (resource-based-view - RBV), que propõe a valorização dos atributos internos da firma como fonte de vantagem competitiva sustentável, tem suas raízes em Penrose (1959). Seu desenvolvimento ocorreu a partir de diversos trabalhos acadêmicos, como os de Wernerfelt (1984), vindo a conhecer um sucesso generalizado nos últimos anos. A noção acabou por se incorporar ao próprio vocabulário dos administradores e dirigentes, a partir do artigo de Hamel e Prahalad, na Harvard Busines Review (1990) e principalmente com o livro que se seguiu ao artigo: Competindo pelo Futuro, 1995. A noção de competência essencial está hoje amplamente difundida e, de certa forma, banalizada.

A primeira autora a utilizar o termo recurso na acepção que lhe é dada hoje na literatura de management foi Edith Penrose (1959) em seu livro The Theory 
of the Growth of the Firm. Penrose sublinha que, na análise da firma pelos modelos estabelecidos, o crescimento é apenas o aumento na oferta de um determinado produto, da mesma forma que o tamanho ideal dessa oferta corresponde ao ponto mínimo da curva de custo. $\mathrm{Na}$ economia ricardiana, a firma está atrelada ao produto, não havendo espaço para analisar a variação no tipo de produto como forma de crescimento. Esta visão da firma não se mostrou adequada ao seu objetivo de entender o processo de crescimento das firmas e os limites para este crescimento. Penrose introduziu, então, um novo conceito de firma, fundamental para o desenvolvimento posterior da abordagem RBV:

“... a firma é mais que uma unidade administrativa; é também uma coleção de recursos produtivos cuja disposição entre diferentes usos e ao longo do tempo é determinada por decisões administrativas." (p.24)

$\mathrm{Na}$ visão de Penrose a delimitação dos recursos de uma firma é, de certa forma, restrita. Ela considera essencialmente os bens tangíveis, como plantas, equipamentos, terras, matérias-primas e outros, além dos recursos humanos disponíveis. Entretanto, Penrose traz uma contribuição fundamental ao sublinhar o fato de que a fonte de individualidade de uma firma não reside no seu conjunto de recursos, mas sim na forma como estes são usados, ou seja, nos serviços gerados. Os recursos, apesar de importantes para o crescimento da firma, são apenas um conjunto de serviços em potencial: a forma como eles serão usados é que definirá a vantagem competitiva de uma firma sobre as demais.

Esses conceitos foram introduzidos no final da década de 1950, mas foi apenas em meados dos anos 1980 que a abordagem baseada na noção de recursos ganhou espaço como uma alternativa estratégica para as firmas. Inicialmente, Nelson e Winter (1982) propõem uma visão evolucionista da firma, que influenciou todo o pensamento neo-schumpeteriano, revalorizando a contribuição de Penrose. Um dos primeiros trabalhos que adotaram explicitamente a denominação resource-based-view foi o de Wernerfelt (1984). Em seu artigo, o autor faz um paralelo entre a visão tradicional baseada em produtos e a visão baseada em recursos, mostrando que neste caso novas perspectivas estratégicas podem ser visualizadas, principalmente para firmas que pretendam diversificar suas atividades para outros mercados. Não há uma preocupação em 
definir formalmente o que sejam os recursos, mas torna-se claro que, além dos ativos tangíveis já citados por Penrose (1959), o autor considera também os ativos intangíveis, principalmente pela ênfase dada à tecnologia como fator importante na estratégia da empresa.

No início da década de 1990, novos estudos no âmbito da RBV foram publicados, apontando para a importância dos recursos específicos da firma para a sua performance. Segundo Barney (1991), para que os recursos de uma firma pudessem ser fonte de vantagem competitiva sustentável, estes deveriam atender a quatro requisitos: serem valiosos, no sentido de explorar as oportunidades do ambiente em que a firma se encontra; serem raros entre as firmas concorrentes; serem de difícil imitabilidade; não possuírem substitutos estrategicamente equivalentes. Assim, as firmas que detêm recursos com estas características e implementam estratégias que os explorem, podem alcançar uma condição privilegiada em relação aos seus concorrentes.

Entre os estudos empíricos realizados sobre o assunto, o de Rumelt (1991) foi bastante significativo, pois mostrou que a diferença de lucro entre firmas pertencentes a uma mesma indústria é maior que entre firmas de indústrias distintas, reforçando a pouca importância da estrutura da indústria frente ao conjunto de recursos pertencentes às firmas. Essa questão tem gerado uma ampla discussão, pois estudos posteriores, como o de McGahan e Porter (1997), tentam mostrar justamente o contrário, ou seja, que a estrutura da indústria é o fator determinante para a rentabilidade das firmas.

O trabalho de Collis e Montgomery (1995) se apresenta como uma síntese da abordagem RBV, uma vez que reúne diferentes conceitos concernentes à teoria que ainda não haviam sido definidos formalmente. Os autores apresentam a RBV não como uma abordagem fechada apenas para os recursos da empresa, mas também voltada para a importância da influência do ambiente competitivo para o sucesso da empresa, como mostra a seguinte afirmativa:

"A RBV combina a análise interna dos fenômenos que ocorrem na firma (...) com a análise externa da indústria e do ambiente competitivo (o foco central das abordagens estratégicas mais recentes). (...) Os recursos não podem ser avaliados isoladamente, porque seu valor é determinado pela interação com as forças de mercado." (p.119-120) 
Torna-se claro que a RBV não se limita a analisar os recursos internos da empresa como muitos autores insistiam em apontar como um ponto fraco da abordagem, uma vez que o ambiente externo também exerce forte influência no desenvolvimento estratégico da empresa.

Mesmo com grande aceitação da abordagem RBV, há ainda hoje uma vultosa discussão em torno dos termos e conceitos introduzidos ao longo do tempo por diferentes autores. Não há um consenso sobre o que seja considerado como um recurso da firma, uma vez que alguns autores se baseiam numa visão mais restrita, como Penrose (1959) e Wernerfelt (1984) e outros consideram um conceito mais amplo, como Barney (1996):

"Em geval, os recursos da firma são todos os ativos, capacitaçōes, competências, processos organizacionais, atributos da firma, informação, conhecimento e tudo mais que é controlado pela firma e que permite a ela conceber e implementar estratégias que aumentem sua eficiência e sua efetividade." (p.144)

Mesmo adotando a conceituação ampla proposta por Barney, a identificação dos recursos que servirão como fonte de vantagem competitiva não é tarefa simples, pois muitas das características que lhe são atribuídas só podem ser percebidas intuitivamente. Como definição geral, um recurso valioso deve contribuir para a produção de algo que os clientes desejem por um preço que estes estejam dispostos a pagar (Collis \& Montgomery, 1995).

Teece et al. (1997), preocupados com a sustentabilidade das vantagens competitivas baseadas nos recursos da firma, propuseram o conceito de capacidades dinâmicas (dynamic capabilities). O termo dinâmico refere-se à habilidade da firma em renovar competências para fazer frente às mudanças do ambiente de negócios. As "capacidades dinâmicas" são de certa forma "capacidades motrizes", sendo estas capazes de renovar as vantagens competitivas das empresas nos ambientes dinâmicos. O ponto central das capacidades dinâmicas compreende os processos organizacionais, moldados pelas posiçôes em ativos e pelos caminhos percorridos pela firma. E é neste ponto que se tornam necessárias as considerações acerca do processo de criação do conhecimento discutido por Nonaka e Takeuchi (1995) e Leonard-Barton (1995). As competências para inovar dependem finalmente da existência de mecanismos e procedimentos 
desenvolvidos pelas firmas que assegurem a sustentação da sua capacidade inovadora, numa perspectiva de criação de novos conhecimentos (Nonaka \& Takeuchi, 1995) ou de aptidões estratégicas (Leonard-Barton, 1995).

\subsection{Uma proposta de avaliação das competências para inovar}

Entretanto, se a noção de competências é bastante rica e apropriada para compreender a dinâmica da inovação dentro de um cenário voltado para a aprendizagem e a criação de conhecimento, parece-nos que a identificação precisa das competências nas empresas e a sua utilização gerencial ainda apresentam problemas decorrentes, em primeiro lugar, como aponta Durand (2000), da ausência de definições claras e operacionais que permitam a aplicação concreta do conceito.

A presente proposta de avaliação das competências para inovar toma como ponto de partida a análise e as proposições de François et al. (1999). Para esses autores, as competências são vistas como pertencendo à empresa. A abordagem privilegiada aqui é a da inovação como finalidade. O ponto central está em perguntar sobre as aptidóes que a priori uma firma deve deter para que a inovação ocorra e seja rentável para a empresa. Essa concepção é coerente com a proposição de Nelson e Winter (1982) que postula a existência de rotinas para inovar como base de atuação das empresas nos ambientes dinâmicos de competição. Assim, deve ser sublinhado que o foco da abordagem não é o de estudar a criação de competências no próprio processo de inovação nem o da identificação de competências de reação que permitem às empresas "enfrentar" melhor do que outras a introdução de uma dada inovação externa à empresa.

François et al. (1999) discutem diversas propostas de questionários visando identificar as competências detidas pelas empresas e avaliar em que grau estas estão efetivamente implantadas como "rotinas para inovação". O presente trabalho adota a versão que François et al. (1999) denominam "questionário competências". ' O questionário limita-se exclusivamente a perguntar aos responsáveis se eles consideram que suas empresas detêm uma lista de competências previamente definidas como base para inovação.

\footnotetext{
Um questionário deste tipo já foi utilizado em pesquisa realizada pelo Ministério da Indústria, em 1997, na França, com 5.000 empresas industriais.
} 
Entretanto, a abordagem oriunda das propostas de François et al. (1999) merece, no nosso entender, algumas considerações. Ao trabalhar com um universo amplo de empresas, de segmentos diferentes e posiçôes diferentes nas cadeias produtivas, a pesquisa realizada permite, sem dúvida, gerar uma visão de conjunto das competências para a inovação, possibilitando, por exemplo, comparações entre países ou identificação de pontos fracos no Sistema Nacional de Inovação. Entendemos, porém, que, tendo em vista a busca de resultados de interesse da gestão da inovação nas empresas e indústrias, a forma adotada deve ser reavaliada e modificada.

Podemos ilustrar o problema com o caso da indústria petroquímica. É possível que a capacidade de inovação efetiva possa estar bloqueada por problemas relacionais. Inovações iniciadas ou tentadas num certo nível a montante da cadeia produtiva podem não se traduzir em resultados no nível dos produtos finais ao serem bloqueadas por ausência de competências em níveis a jusante. Um novo tipo de plástico, por exemplo, desenvolvido como uma inovação por uma empresa petroquímica pode não aparecer nos objetos e peças produzidos a partir dele devido a problemas na transformação do material, que é realizada por empresas a jusante das empresas petroquímicas na cadeia produtiva. Em outros termos: a competência para inovar de uma empresa ou empresas de uma certa indústria está limitada pelas competências de atores nos demais níveis de atuação nas cadeias, sendo que essas competências englobam dimensões tecnológicas, mas também organizacionais no interior de cada empresa e relacionais (nível das relaçôes entre empresas). Na realidade, o estudo da dinâmica de inovação na indústria química (Bomtempo, 1994; Arora et al., 1998) mostra diversas situações nas quais as empresas inovadoras se viram na obrigação de resolver problemas decorrentes de competências ausentes em outros níveis da cadeia produtiva para concretizarem as inovações pretendidas. Esses problemas para a concretização das inovações foram caracterizados por Teece (1992), como relacionados à presença e ao controle dos chamados ativos complementares. A questão dos ativos complementares traz às competências para inovar a necessidade de compreender e tratar adequadamente o papel exercido por atores não pertencentes diretamente à indústria em estudo. Nesse ponto, a gestão das relações com as possíveis fontes da inovação, no sentido proposto por von Hippel (1988), deve ser incorporada nas competências inovadoras. 


\section{Metodologia}

A pesquisa foi realizada através de uma survey. O principal motivo para tal escolha está no fato de que informações a respeito das competências para inovar na indústria petroquímica brasileira não estão disponíveis por meio de nenhuma outra fonte, o que torna necessária a coleta de dados diretamente do universo que se pretende estudar. A pesquisa foi feita com base num questionário adaptado de uma proposta geral de François et al. (1999), com o objetivo de identificar e medir o nível de desenvolvimento das competências para inovar na indústria petroquímica brasileira. Este questionário foi modificado para captar a dinâmica de inovação da indústria petroquímica. Foram incluídas, em particular, competências referentes às fontes da inovação, destacando as relações de cooperação com os participantes da cadeia petroquímica, que não tinham sido consideradas na pesquisa original.

\subsection{Seleção da amostra}

As empresas foram selecionadas com base no seu grau de importância dentro da indústria petroquímica brasileira. Com base nos anuários da ABIQUIM (Associação Brasileira da Indústria Química), os questionários foram enviados para as 11 maiores empresas petroquímicas de capital nacional. ${ }^{2}$ Foram obtidas respostas de nove empresas, o que representa cerca de $90 \%$ do faturamento da amostra e $75 \%$ da indústria petroquímica como um todo, considerando-se as empresas de controle estrangeiro presentes na indústria. As respostas incluem produtores de petroquímicos básicos, intermediários e produtos finais, representando os diversos papéis que as empresas dessa indústria exercem na cadeia produtiva.

2 Foram consideradas empresas de capital nacional aquelas em que mais de $50 \%$ do controle acionário pertence ao capital nacional. Seguindo o mesmo raciocínio, empresas de capital estrangeiro são aquelas em que mais de $50 \%$ do controle acionário pertence ao capital estrangeiro.

Ao longo deste trabalho, será utilizado o termo indústria petroquímica brasileira sempre se referindo às empresas petroquímicas de capital nacional que atuam no Brasil. Isto se deve ao fato da seleção da amostra utilizada para o presente estudo ter seguido este critério. 


\subsection{Construção do questionário}

Como explicado na seção anterior, a pesquisa foi feita com base num questionário, adaptado de uma proposta geral de François et al. (1999), com o objetivo de identificar e medir o nível de desenvolvimento das competências para inovar na indústria petroquímica brasileira.

São considerados inicialmente dez grupos de competências ditas "complexas" que englobam o conjunto idealizado de competências para inovar. São as seguintes: inserir a inovação na estratégia de conjunto da empresa; seguir, prever e agir sobre a evolução dos mercados; desenvolver as inovações; organizar e dirigir a produção de conhecimento; apropriar-se das tecnologias externas; gerir e defender a propriedade intelectual; gerir os recursos humanos numa perspectiva de inovação; financiar a inovação; vender a inovação; cooperar para inovação. Para a elaboração do questionário, cada uma das competências complexas mencionadas foi desdobrada em competências operacionais ou elementares, que, em conjunto, traduziriam o nível de desenvolvimento da competência complexa em análise. Foram consideradas, no total, 68 competências operacionais. A título de ilustração, o Quadro 1 apresenta a estrutura hierárquica descrita para a competência "Seguir, prever e agir sobre a evolução dos mercados". Utilizam-se nesse caso sete perguntas objetivas, referindo-se a competências operacionais, que devem permitir a avaliação da competência complexa em questão. Esse procedimento se repete para cada uma das dez competências examinadas.

O questionário foi validado para a indústria petroquímica com base em estudos que analisam a dinâmica de competição e inovação na indústria, cobrindo para a última década tanto as perspectivas nacionais quanto internacionais da indústria (Coutinho, 2004; Bomtempo, 1994; Arora, et al., 1998).

Os respondentes avaliaram o grau de consolidação dessas competências em suas empresas, atribuindo um grau de zero a cinco a cada uma delas. Naturalmente, pode-se discutir o grau de subjetividade com que cada responsável julga se sua empresa possui ou não, e em que nível, determinada competência. Acresce que, no caso de empresas de grande porte, a própria função do respondente pode representar um certo viés nas respostas. A forma de execução da pesquisa procurou amenizar tais problemas. 
QUADRO I

Estrutura do questionário "Competências para inovar"

(ilustração para uma competência)

III) Seguir, prever e agir sobre a evolução dos mercados

Seguir os produtos concorrentes

Conhecer a demanda latente não satisfeita e as reações do cliente à introdução de inovações:

Competências operacionais pesquisadas:

1 - sua empresa analisa os produtos concorrentes?

2 - sua empresa analisa as patentes dos seus concorrentes?

3 - sua empresa analisa as publicações dos profissionais dos concorrentes?

4 - sua empresa analisa a segmentação e as necessidades da clientela?

5 - sua empresa procura conhecer junto ao serviço pós-venda ou distribuidores as reações da clientela?

6 - sua empresa tem conhecimentos sobre as necessidades dos clientes dos seus clientes?

7 - Sua empresa identifica as necessidades emergentes ou os comportamentos de consumo pioneiros?

Fonte: elaboração própria.

\subsection{Execução da pesquisa}

Foram escolhidos como respondentes os responsáveis diretos pela implementação da política de P\&D das empresas: julgou-se que, dadas as características tecnológicas das empresas estudadas, a direção de $\mathrm{P} \& \mathrm{D}$ deteria uma visão geral da inovação nas empresas. Entretanto, devido à diversidade de cultura e estruturas organizacionais encontradas, a pesquisa envolveu pessoas de diferentes níveis hierárquicos, incluindo diretores, gerentes e coordenadores de área.

O mecanismo de envio e coleta das respostas foi personalizado e compreendeu duas etapas. Inicialmente, o questionário era entregue após um primeiro contato, no qual os objetivos da pesquisa e os principais conceitos utilizados eram apresentados e discutidos. Os representantes das empresas ficavam com 
o material para posterior envio das respostas. Recebidas e analisadas as respostas, estabelecia-se um novo contato (pessoal ou telefônico) de forma a dirimir dúvidas e corrigir eventuais contradições encontradas. Esse procedimento visava garantir que as respostas refletissem efetivamente a visão das empresas, ou, pelo menos, a dos responsáveis pela $\mathrm{P} \& \mathrm{D}$.

\section{Análise e discussão dos resultados}

Os resultados obtidos serão analisados sob duas óticas. Na primeira, discutiremos as competências agrupadas segundo os dez grupos de competências complexas do questionário. Na segunda ótica de análise, as 68 competências operacionais serão classificadas segundo a sua natureza, distinguindo de forma geral as competências técnicas, organizacionais, relacionais e de meios. Como o estudo das competências segundo a sua natureza evidencia a importância crítica das competências organizacionais, essas serão por fim analisadas em particular.

\subsection{Análise dos resultados segundo os grupos de competências complexas}

Antes de avaliar as competências, foi perguntado se as empresas tinham inovado nos últimos três anos. Todas responderam afirmativamente, tanto em processos como em produtos, o que demonstra que a amostra em análise é homogênea neste aspecto.

A Tabela 1 apresenta as notas médias obtidas pelas empresas para cada uma das competências analisadas. Os valores representam as médias das competências operacionais que compõem cada um dos dez grupos de competências complexas. Observa-se que a preocupação em inserir a inovação na estratégia da empresa se destaca, embora os mecanismos que poderiam traduzir essa preocupação em inovações efetivas pareçam menos desenvolvidos, em particular os pontos referentes à produção de conhecimento e à gestão de recursos humanos e da propriedade intelectual. Com o objetivo de apresentar uma visão geral dos pontos fortes e fracos das competências para inovar da indústria petroquímica brasileira, mostra-se a seguir uma análise descritiva das competências que apresentam os valores médios mais elevados e os mais baixos. 
A competência "Inserir a inovação na estratégia de conjunto da empresa" foi detectada como a mais desenvolvida na petroquímica brasileira. Isso denota que as empresas possuem, em geral, capacidade para se transformarem ou se adaptarem. Todas têm um bom nível de controle sobre a qualidade e a eficácia de seus produtos $(4,7 / 5)^{3}$ e costumam avaliar periodicamente os seus processos produtivos $(3,8 / 5)$. É possível identificar, a partir das entrevistas, uma busca pelo estabelecimento de benchmarkings, inclusive com empresas internacionais. Constata-se, entretanto, uma certa deficiência na avaliação e implementação de novas estruturas organizacionais $(2,7 / 5)$, o que pode comprometer a capacidade de inovar, em face da constante evolução dos mercados. Da mesma forma, as respostas parecem indicar que o levantamento das competências do pessoal (2,7/ 5) e a difusão de uma visão global das atividades e negócios entre os empregados $(2,7 / 5)$ devem ser melhorados. As entrevistas com os respondentes confirmam a última constatação. Efetivamente, as estratégias das empresas, quando existem de forma explícita, são pouco difundidas entre os níveis hierárquicos.

As competências de valores médios mais elevados que vêm a seguir são as do grupo "Financiar a inovação". Elas podem ser consideradas, em média, aceitáveis na indústria $(2,9 / 5)$. Todas as empresas conhecem e mantém contato com as fontes de financiamento público e privado para a inovação $(4,3 / 5)$. As empresas avaliam antecipadamente (2,7/5), de forma sistemática, o conjunto de custos ligados à inovação, apesar dessa preocupação ser ignorada por três delas. A avaliação a posteriori dos custos de uma inovação é uma preocupação importante para apenas duas empresas $(1,1 / 5)$.

Por outro lado, entre as competências menos desenvolvidas destacam-se as dos grupos "Organizar e dirigir a produção de conhecimento" e "Gerir e defender a propriedade intelectual”. O nível de desenvolvimento das competências para "Organizar e dirigir a produção de conhecimento" é particularmente baixo na indústria petroquímica brasileira $(1,9 / 5)$. As respostas obtidas ao questionário indicam estruturas/culturas organizacionais com baixa capacidade de organização e direção da produção do conhecimento, gerando um ambiente com pouco incentivo à inovação. Não são avaliadas a contribuição individual

\footnotetext{
3 Os valores entre parênteses referem-se ao valor médio da competência descrita no texto em relação ao valor máximo possível, o qual para esta pesquisa foi sempre 5. Por exemplo, a competência "Ter um bom nível de controle sobre a qualidade e a eficácia de seus produtos" obteve média 4,7 e o valor máximo que ela poderia atingir seria 5. O valor apresentado ao comentá-la aparece, assim, $(4,7 / 5)$.
} 
TABELA 1

Competências para inovar da indústria petroquímica brasileira (notas médias, máximo 5)

Competência

Média

1 - Inserir a inovação na estratégia de conjunto da empresa

2 - Seguir, prever e agir sobre a evolução dos mercados

3 - Desenvolver as inovações

4 - Organizar e dirigir a produção de conhecimento

5 - Apropriar-se das tecnologias externas

6 - Gerir e defender a propriedade intelectual

7 - Gerir os recursos humanos numa perspectiva de inovação

8 - Financiar a inovação

9 - Vender a Inovação

à produção de conhecimento $(0,0 / 5)$ e a produção coletiva de conhecimento em relação aos concorrentes $(0,0 / 5)$. Apenas duas empresas declararam incentivar de forma sistemática a geração de novas idéias e promover o compartilhamento do conhecimento. O grau de autonomia para inovação é elevado $(3,4 / 5)$, porém a aceitação de comportamentos criativos, não diretamente produtivos, $(2,2 / 5)$ e a valorização da originalidade e da criatividade na avaliação individual $(2,3 / 5)$ são notavelmente reduzidas. De uma forma geral, as empresas não premiam as idéias originais quando adotadas $(1,6 / 5)$.

As competências que constituem a capacidade de "Gerir e defender a propriedade intelectual” mostram-se igualmente deficientes (2,0/5). Em geral, há uma baixa preocupação com a existência e a difusão de cópias $(1,6 / 5)$ e com combate na justiça das cópias e imitações $(1,3 / 5)$. As empresas não têm preocupação em desvalorizar as cópias e imitações junto aos clientes $(1,0 / 5)$. Há que se melhorar na identificação e motivação das pessoas que detém os conhecimentos e know-how estratégicos $(2,8 / 5)$ e também na identificação $(2,4 / 5)$, 
na proteção $(2,6 / 5)$ e na manutenção $(1,8 / 5)$ desses conhecimentos. Convém lembrar que a pouca importância dada a essas competências pode significar a transferência e, portanto, a perda para o mercado ou para os concorrentes de vantagens competitivas obtidas com elevado esforço.

$\mathrm{Na}$ discussão acima, as competências foram agrupadas segundo dez grupos temáticos de competências complexas. A análise com base nos grupos, entretanto, evidencia que um mesmo grupo compreende competências operacionais de natureza diversa. "Desenvolver as inovaçôes", por exemplo, depende tanto de competências voltadas para o favorecimento do trabalho em equipe quanto da capacidade de adquirir rapidamente equipamentos e insumos tecnologicamente novos. Propõe-se então, a seguir, uma análise das 68 competências elementares pesquisadas, segundo sua natureza.

\subsection{Análise segundo a natureza das competências}

As competências para inovar podem ser agrupadas, segundo Munier (1999), em quatro grupos distintos: técnicas, organizacionais, relacionais e de meios.

As competências organizacionais são as que favorecem a criação de novos conhecimentos, segundo o modelo de Nonaka e Takeuchi (1995). Inclui as que dizem respeito à gestão dos recursos humanos e as relacionadas à inovação em uma dimensão transversal no interior da firma. As competências relacionais são aquelas que atuam sobre os mercados (relações com o ambiente concorrencial e com a demanda) e aquelas relacionadas à capacidade da empresa de cooperar, formar alianças e se apropriar de tecnologias externas. As competências técnicas, por sua vez, são as competências relacionadas à gestão da produção e das tecnologias, essencialmente dentro da firma. As competências de meios são as que permitem à empresa fazer P\&D, obter financiamentos e/ou vender a inovação. São as competências que permitem a mobilização dos recursos da empresa para desenvolver uma inovação e sua capacidade de arcar com os custos que resultam desse desenvolvimento.

O primeiro passo na análise estatística foi comprovar que a amostra em estudo seguia uma distribuição normal. Este é um pré-requisito para a realização de testes t (Hair, 1995), utilizados para o teste de hipóteses. Para a comprovação, foi realizado o teste Shapiro-Wilk para cada um dos grupos de competências a 
serem estudados, e em todos eles ficou constatado que a amostra seguia a distribuição normal. Este teste, bem como todas as demais análises que serão apresentadas a seguir foram feitas utilizando-se o software Statistica.

A Tabela 2 apresenta os resultados estatísticos descritivos para cada um dos grupos de competências mencionados acima. A partir desta, é possível observar que as competências técnicas têm valor médio superior aos demais grupos de competências, sendo o único grupo a assumir um valor superior a 3.

TABELA 2

Estatísticas descritivas segundo os grupos de competências para inovar

\begin{tabular}{|c|c|c|c|c|c|c|}
\hline & Média & Mínimo & Máximo & $\begin{array}{l}\text { Quartil } \\
\text { inferior }\end{array}$ & $\begin{array}{l}\text { Quartil } \\
\text { superior }\end{array}$ & $\begin{array}{l}\text { Desvio } \\
\text { padrão }\end{array}$ \\
\hline Competências técnicas & 3,33 & 1,90 & 4,60 & 2,70 & 4,30 & 0,954580 \\
\hline Competências organizacionais & 2,35 & 0,60 & 3,60 & 1,20 & 3,10 & 1,042699 \\
\hline Competências relacionais & 2,72 & 0,90 & 4,30 & 2,10 & 3,70 & 1,090158 \\
\hline Competências de meios & 2,48 & 1,50 & 3,90 & 1,80 & 2,80 & 0,784290 \\
\hline
\end{tabular}

Fonte: elaboração própria utilizando os resultados do soffware Statistica.

Tomando por base os percentis mostrados na Tabela 2, observa-se que a distribuição das respostas é bastante diferente entre as competências técnicas e os demais grupos de competências.

No que diz respeito às competências técnicas, mais de $75 \%$ da amostra estaria acima do valor 2 de resposta, o que significa dizer que menos de $25 \%$ das empresas teriam competências técnicas em níveis muito baixos. Ao contrário, nos demais grupos de competências, menos de $25 \%$ das empresas deteriam as competências em níveis elevados, acima de 4, demonstrando uma diferença entre o nível de competências de natureza técnica e as demais. Estes resultados 
parecem apontar para uma significativa diferença entre o nível das competências técnicas e o dos demais grupos (competências organizacionais, relacionais e de meios) na indústria petroquímica brasileira.

Para confirmar a veracidade de tal tendência, foram realizados testes de hipótese entre os grupos de competências. A hipótese nula seria de que todos os grupos possuem média igual estatisticamente, ou seja, não há diferenças entre as competências dos quatro grupos detidas pelas empresas. A rejeição da hipótese nula indicaria entre quais grupos existe uma diferença estatisticamente significativa no nível das competências.

\section{TABELA 3}

Teste de hipóteses segundo os grupos de competências para inovar (os valores marcados são significativos para $p<0,05000$ )

\begin{tabular}{lcccc} 
Variável & $\begin{array}{c}\text { Competências } \\
\text { técnicas }\end{array}$ & $\begin{array}{c}\text { Competências } \\
\text { organizacionais }\end{array}$ & $\begin{array}{c}\text { Competências } \\
\text { relacionais }\end{array}$ & $\begin{array}{c}\text { Competências } \\
\text { de meios }\end{array}$ \\
Competências técnicas & 1,000000 & 0,029748 & 0,100335 & 0,017131 \\
Competências organizacionais & 0,029748 & 1,000000 & 0,028683 & 0,611717 \\
Competências relacionais & 0,100335 & 0,028683 & 1,000000 & 0,293422 \\
Competências de meios & 0,017131 & 0,611717 & 0,293422 & 1,000000 \\
\hline
\end{tabular}

Fonte: elaboração própria utilizando os resultados do software Statistica.

De acordo com os resultados mostrados acima, a hipótese nula é rejeitada para uma função de probabilidade menor que $5 \%$ quando se comparam as competências técnicas com as organizacionais e com as de meios. Isto significa que a diferença entre elas é estatisticamente significativa. No caso da comparação entre competências técnicas e relacionais, o resultado mostra que para uma função de probabilidade maior que $95 \%$ não há diferença estatística entre as médias dos grupos. No entanto, se considerarmos uma função de probabilidade maior que $90 \%$, já é possível apontar para uma diferença estatisticamente significativa 
também entre estes dois grupos de competências. Mesmo assim, os resultados apontam que as competências de natureza relacional não se encontram em níveis muito mais baixos do que as técnicas, possivelmente não sendo a principal responsável pelo perfil pouco inovador das empresas estudadas. Ainda analisando as competências relacionais, os resultados mostram que estas se encontram em níveis semelhantes aos das competências de meios para uma função de probabilidade maior que $95 \%$, mas são estatisticamente mais elevadas que as competências organizacionais. Os resultados apontam que, apesar de dispor de competências de atuação sobre os mercados, são claras as deficiências quanto à formação de alianças e em diversos aspectos da apropriação de tecnologias externas. As empresas se mostram com competências desenvolvidas no que diz respeito ao seu relacionamento com seus clientes e com os clientes de seus clientes, assim como atentas aos novos produtos lançados por concorrentes. No entanto, as competências relacionais voltadas para a cooperação, seja através de iniciativas para financiamento de novos projetos ou aproximação com outras empresas (fornecedores, clientes e, principalmente, concorrentes) para a formação de alianças para novos desenvolvimentos, são bastante deficientes.

No que diz respeito às competências de meios, estas só se mostram estatisticamente diferentes em relação às competências técnicas, mostrando-se em patamar de igualdade ao serem comparadas com as competências relacionais e organizacionais. Seu valor médio encontra-se entre os valores médios dos grupos citados, não sendo encontradas diferenças significativas nesta comparação. As notas atribuídas às competências de meios apontam para uma fragilidade das empresas que resultaria principalmente das notórias dificuldades em relação à realização de $\mathrm{P} \& \mathrm{D}$. As empresas procuram passar uma imagem inovadora, mas não parecem ter atingido ainda um nível de desenvolvimento aceitável em competências que as permitam avaliar e controlar os custos da inovação. Essa dificuldade é notória tanto antes do início do processo de inovação quanto após o seu término. Por certo, as deficiências nas competências de meios tornam difícil o planejamento em longo prazo das atividades de P\&D, ou mesmo adquirir outras empresas como forma de inovar.

Finalmente, as deficiências da indústria petroquímica brasileira são fortemente notadas no campo das competências organizacionais. Os resultados mostram que as competências organizacionais possuem um grau de desenvolvimento 
estatisticamente inferior tanto em relação às competências técnicas quanto às relacionais. Apenas em relação às competências de meios não existe diferença estatisticamente significativa para uma função de probabilidade maior que $95 \%$. $\mathrm{Na}$ seção seguinte, as competências organizacionais são estudadas com maior profundidade.

\subsection{Análise das competências organizacionais}

As competências organizacionais referem-se à capacidade de geração de conhecimento e à gestão de recursos humanos, que surgem como pontos centrais das deficiências da indústria em termos de competências para inovar. Entre as 68 competências operacionais que compõem o questionário aplicado, 32 são de conteúdo predominantemente organizacional. Essas competências são estudadas a seguir, buscando evidenciar que dimensões organizacionais são particularmente deficientes.

As competências organizacionais, segundo Munier (1999), podem ser subdivididas em três grupos. O primeiro (grupo I) seria formado pelas competências que favorecem a criação de novos conhecimentos, dando-se importância às interaçóes entre os indivíduos e sua autonomia. O segundo (grupo II), englobaria as competências que favorecem a dimensão transversal da inovação. São as competências que, presentes nas diversas funções da empresa, permitem a transferência/troca de informações e conhecimentos necessários à inovação. $\mathrm{O}$ terceiro (grupo III) seria formado pelas competências de identificação e avaliação do saber individual e coletivo.

Esta subdivisão permite uma analogia ao modelo de criação do conhecimento de Nonaka e Takeuchi (1995). Segundo estes autores, a criação do conhecimento está baseada na mobilização e conversão do conhecimento tácito, ou seja, do conhecimento detido pelos indivíduos que compõem a empresa. O conhecimento é criado inicialmente no nível dos indivíduos. A empresa apóia os indivíduos criativos proporcionando condições para a criação do conhecimento. Em uma etapa seguinte, o conhecimento tácito se transforma em conhecimento explícito. Este, depois de combinado a outros conhecimentos explícitos gera o novo conhecimento, o qual é transmissível em linguagem formal e sistemática, podendo ser internalizado e assim contribuir para o au- 
mento do próprio nível de conhecimento tácito. A partir destas etapas, à medida que a interação entre conhecimento tácito e conhecimento explícito eleva-se dinamicamente de um nível individual para um nível organizacional, surge a espiral do conhecimento proposta por Nonaka e Takeuchi (1995).

Assim, o grupo I das competências organizacionais é formado essencialmente por competências elementares relacionadas à criação do conhecimento no nível dos indivíduos dentro da empresa, como, por exemplo, o incentivo a novas idéias, a autonomia para cada empregado inovar e a garantia da conservação, por parte da empresa, do conhecimento estratégico em caso de saída de um empregado. As competências relacionadas a este grupo referem-se predominantemente às dimensões tácitas do conhecimento. Já o grupo II envolve competências relacionadas ao conhecimento explícito, como a estruturação da empresa em torno dos projetos de inovação, a implicação de todos os serviços nos projetos desde o início e o controle da propriedade intelectual. Finalmente, o grupo III é formado pelas competências que possibilitam a identificação e avaliação do saber, tanto individual quanto coletivo, sendo um grupo fundamental para que a criação do conhecimento aconteça, pois o apoio da empresa ao conhecimento dos indivíduos para a sua propagação a um nível coletivo só é possível se forem bem desenvolvidas as competências deste grupo.

A Tabela 4 apresenta os resultados estatísticos descritivos encontrados para os grupos de competências organizacionais. O grupo II é o que apresenta a média mais elevada. O valor médio é mais elevado até mesmo em comparação com as competências relacionais e de meios, mostradas anteriormente na Tabela 1. Os valores médios das competências organizacionais do grupo II são inferiores apenas aos das competências técnicas, sugerindo, de certa forma, que as questôes relacionadas ao conhecimento explícito não são as fontes mais importantes das deficiências organizacionais das empresas. No entanto, é possível notar que o grupo II é o que apresenta o maior intervalo de distribuição, com valor mínimo de 0 e máximo de 4,5 na escala de resposta. Isto mostra que há empresas com este grupo de competências muito bem desenvolvido ao passo que, em outras, estas competências ainda estão incipientes. Há uma grande heterogeneidade nas competências em questão, apesar da alta média apresentada.

O grupo I apresenta uma média no mesmo patamar do grupo de competências organizacionais como um todo, estando, desta forma, com valores 
semelhantes aos das competências relacionais e de meios. Em relação às competências ligadas ao conhecimento tácito, as empresas apresentam um nível pouco satisfatório, mas não discrepante dos demais grupos de competências, excluindo-se as competências técnicas.

O grupo III é o que apresenta a menor média, sugerindo deficiências importantes na gestão dos recursos humanos. Na totalidade das empresas estudadas, a nota média para este grupo se manteve abaixo de 2. Além disso, observase que o intervalo de distribuição é um dos maios restritos, apontando para uma alta homogeneidade entre as empresas, ou seja, na maioria delas este grupo de competências está muito pouco desenvolvido.

TABELA 4

Estatísticas descritivas para os grupos de competências organizacionais

\begin{tabular}{|c|c|c|c|c|c|c|}
\hline & Média & Mínimo & Máximo & $\begin{array}{l}\text { Quartil } \\
\text { inferior }\end{array}$ & $\begin{array}{l}\text { Quartil } \\
\text { superior }\end{array}$ & $\begin{array}{l}\text { Desvio } \\
\text { padrão }\end{array}$ \\
\hline \multirow[t]{2}{*}{ Competências organizacionais } & 2,35 & 0,60 & 3,60 & 1,20 & 3,10 & 1,042699 \\
\hline & 2,46 & 0,50 & 4,00 & 1,10 & 3,40 & 1,220382 \\
\hline Grupo II & 2,95 & 0,00 & 4,50 & 2,30 & 3,80 & 1,309156 \\
\hline Grupo III & 1,94 & 0,40 & 3,60 & 0,70 & 2,60 & 1,069995 \\
\hline
\end{tabular}

Fonte: elaboração própria utilizando os resultados do software Statistica.

Os resultados descritivos acima levam-nos a testar a hipótese da diferença estatisticamente significativa entre os três grupos de competências organizacionais. A hipótese nula considerada é, portanto, que as médias dos grupos são estatisticamente iguais. Os resultados dos testes de hipótese são apresentados na Tabela 5. A partir destes, é possível afirmar que os grupos I e II têm médias estatisticamente iguais, ao passo que o grupo III tem média estatisticamente diferente dos dois primeiros. 
TABELA 5

Teste de hipóteses para os grupos de competências organizacionais

Variável

Subgrupo 1

Subgrupo 2

0,116997

1,000000

0,008271

0,013792

Fonte: elaboração própria utilizando os resultados do software Statistica.

Estes resultados mostram que a hipótese nula é rejeitada em relação às competências do grupo III cujas notas seriam estatisticamente inferiores as demais. Poderíamos assim identificá-las como sendo o ponto mais fraco nas competências para inovar das empresas petroquímicas brasileiras. As empresas apresentam níveis muito baixos nas competências que possibilitam a identificação e avaliação do saber, tanto individual quanto coletivo. Não existiria nas empresas a preocupação em desenvolver procedimentos organizacionais para realizar a identificação e a avaliação do conhecimento detido, tanto no nível individual quanto no nível organizacional. Isto pode ser observado nos baixos valores das respostas dadas pelas empresas nas competências elementares relativas a este grupo, como por exemplo, avaliar a contribuição de cada um na produção do conhecimento; avaliar na contratação a propensão à inovar; identificar as pessoas que detêm os conhecimentos estratégicos; avaliar a necessidade de formação de cada indivíduo para a inovação. Todas estas competências elementares tiveram valor médio de resposta próximo a 0 . Isso se traduz em uma limitação fundamental para que a criação de novos conhecimentos organizacionais aconteça, na perspectiva de Nonaka e Takeuchi (1995), comprometendo, desta forma, o processo de inovação dentro da empresa. 


\section{Conclusão}

Este trabalho apresentou uma proposta de avaliação das competências para inovar que tem como objetivo identificar e medir o grau de desenvolvimento das competências detidas pelas empresas, tendo em vista sua capacidade para inovar. O questionário proposto se limita a questionar as empresas sobre a posse ou não de um determinado bloco de competências que se supõem sejam requisitos para inovação na indústria em questão. A forma do questionário pode ser aprimorada, mas os resultados iniciais sugerem que este permite traçar um quadro bastante nítido da capacidade inovadora de uma indústria. Desta forma, é possível considerar que a proposta conseguiu atingir seus objetivos, mostrando que seria interessante a sua utilização em outros setores industriais.

O questionário foi aplicado na indústria petroquímica brasileira, excluindo-se as empresas de capital estrangeiro. A análise das respostas trouxe à luz alguns pontos sobre a capacidade de inovação da indústria, apontando para as áreas onde há uma maior deficiência nas competências para inovar. Em primeiro lugar, o nível técnico atual da indústria não pode ser considerado deficiente. A indústria demonstra níveis de competência que parecem aceitáveis nesse quesito.

Entretanto, as competências organizacionais revelam-se, em linhas gerais, mais fracas. As empresas parecem ser particularmente deficientes em sua capacidade de identificar e avaliar o saber individual e coletivo, o que fragiliza o processo de criação do conhecimento dentro de cada empresa.

De acordo com os resultados encontrados, as empresas do setor petroquímico brasileiro precisariam concentrar esforços no aprimoramento de suas competências organizacionais com o intuito de alcançarem uma maior capacidade inovadora, em particular nas dimensões relacionadas à gestão dos recursos humanos voltadas para a identificação e avaliação do conhecimento.

Habitualmente, atribui-se a limitação da capacidade inovadora da petroquímica brasileira a uma insuficiência em seus investimentos em tecnologia. Os baixos níveis de gastos com P\&D e a dependência de tecnologias externas mesmo em projetos relativamente convencionais atestariam, segundo a visão corrente dos estudiosos da indústria, as deficiências maiores da petroquímica. Os resultados deste trabalho, entretanto, sugerem uma perspectiva adicional na percepção da capacidade inovadora da indústria. Mesmo que as empresas au- 
mentem os recursos aplicados em P\&D e procurem dar à tecnologia um lugar de destaque na sua gestão, os resultados em termos de inovação podem não ser os esperados, face principalmente às deficiências constatadas em algumas competências organizacionais críticas na criação de novos conhecimentos. Em outras palavras, no estágio tecnológico atual da indústria parece que esforços nas dimensôes organizacionais poderiam aumentar de forma significativa a capacitação inovadora da petroquímica brasileira.

Em síntese, a visão que emerge da indústria petroquímica brasileira, a partir da pesquisa feita, é a de uma indústria que não pode ser considerada destituída de competências para inovar, mas são competências excessivamente centradas no presente. Faltam à indústria justamente as competências necessárias para construir o seu futuro. Isso sugere que seria interessante explorar em pesquisas posteriores a presença ou não de um pensamento estratégico que incorpore uma perspectiva de crescimento e autoperpetuação nas empresas da indústria. Estariam aí as origens das dificuldades e deficiências da indústria petroquímica brasileira?

\section{Referências bibliográficas}

Arora, A.; Landau, R.; Rosenberg, N., Chemicals and Long-term Economic Growth: Insights from the Chemical Industry, Nova York: John Wiley, 1998.

Barney J. B., "Firm Resources and Sustained Competitive Advantage", in Journal of Management, 17, p.99-129, 1991.

, Gaining and Sustaining Competitive Advantage, Addison-Wesley, 1996.

, "Resource-based Theories of Competitive Advantage: a ten-year retrospective on the resource-based view", in Journal of Management, 27, p.643650, 2001.

Barros, H., Gestão de Pesquisa e Desenvolvimento: caso da indústria brasileira de polimeros., Dissertação de Mestrado: IMA, Universidade Federal do Rio de Janeiro, 1998. 
Bomtempo J. V., Innovation et Organisation, le Cas de l Industrie des Polymères. Tese (Doutorado em Economia Industrial) - CERNA/ École des Mines de Paris, 1994.

Collis, D.; Montgomery, C., "Competing on Resources: Strategy in the 1990s", in Harvard Business Review, jul./ago., p.118-128, 1995.

Coutinho, P., Estratégia Tecnológica e Gestão da Inovação: uma estrutura analítica voltada para os administradores, Tese de doutorado, EQ: Universidade Federal do Rio de Janeiro, 2004.

Durand, Th., "L'alchimie de la compétence", in Revue française de gestion, jan.fev., p.84-102, França, 2000.

Figueiredo, P., "Learning, Capability Accumulation and Firm Differences: evidence from latecomer steel", in Industrial and Corporate Change, v.12, n.3, p.607643, 2001.

, "Does technological learning pay off? Inter-firm differences in technological capability-accumulation paths and operational performance improvement", in Research Policy, 31, p.73-94, 2002.

François J.-P.; Goux, D.; Guellec, D.; Kabla, I.; Templé, Ph., "Décrire les compétences pour l'innovation: une proposition d'enquête", in Foray, D.; Mairesse, J. (orgs.), Innovations et performances, approches interdisciplinaires, Paris: Éditions EHESS, 1999.

Hair, J.; Rolph, E.; Anderson, R. L.; Tatham, W. C. B., Multivariate Data Analysis: with readings; $4^{a}$ ed., Nova Jersey: Prentice-Hall, 1995.

Hamel, G.; Prahalad, C. K., "The Core Competence of the Corporation", in Harvard Business Review, p.79-91, 1990.

, Competindo pelo futuro, Rio de Janeiro: Editora Campus, 1995.

Kim, L., "Building Technological Capability for Industrialization: Analytical Frameworks and Korea Experience", in Industrial and Corporate Change, 8, 1, mar., 1999.

Leonard-Barton, D., Wellsprings of Knowledge: building and sustaining the sources of innovation, Boston: Harvard Business School Press, 1995. 
McGahan, A. M.; Porter, M., "How Much does Industry Matter, Really?", in Strategic Management Journal, 18, p.15-30, 1997.

Munier F., Taille de la Firme et Innovation: approches théoriques et empiriques fondées sur le concept de compétence, Tese de Doutorado em Ciências Econômicas, Estrasburgo: Université Louis Pasteur, 1999.

Nelson, R.; Winter, S., An Evolutionary Theory of Economic Change, Cambridge: Harvard University Press, 1982.

Nonaka; I.; Takeuchi, H., The Knowledge-Creating Company, Nova York: Oxford University Press, 1995.

Pavitt, K., "Innovating Routines in the Business Firm: what corporate tasks should they be accomplishing?", in Industrial and Corporate Change, 11 (1), p.117133, 2002.

Penrose, E., The Theory of the Growth of the Firm, Nova York: John Wiley, 1959.

Rumelt, R. P., "How Much does Industry Matter?", in Strategic Management Journal, 12(3), p.167-185, 1991.

Santana, L. M. de; Hasenclever, L.; Mello, J. M. C. de, "Capacitação Tecnológica e Competitividade na Petroquímica Brasileira nos Anos 1990: o caso de Camaçari - BA", in Revista Brasileira de Inovação, v.2, n.1, jan./jun., 2003.

Teece, D., "Strategies for Capturing Financial Benefits from Technological Innovation", in Technology and the Wealth of Nations, California: Stanford University Press, 1992.

; Pisano, G.; Shuen, A., "Dynamic Capabilities and Strategic Management”, in Strategic Management Journal, 18:7, p.509-533, 1997.

von Hippel E., The Sources of Innovation, Nova York: Oxford University Press, 1988.

Wernerfelt, B., "A Resource-based View of the Firm", in Strategic Management Journal, 5, 2, p.171-180, 1984. 